This item was submitted to Loughborough's Research Repository by the author.

Items in Figshare are protected by copyright, with all rights reserved, unless otherwise indicated.

\title{
Mechanical and electrical characterisation of Au wire interconnects in electronic packages under the combined vibration and thermal testing conditions
}

\section{PLEASE CITE THE PUBLISHED VERSION}

http://dx.doi.org/10.1016/j.microrel.2015.02.023

\section{PUBLISHER}

(C) Elsevier

\section{VERSION}

AM (Accepted Manuscript)

\section{PUBLISHER STATEMENT}

This work is made available according to the conditions of the Creative Commons Attribution-NonCommercialNoDerivatives 4.0 International (CC BY-NC-ND 4.0) licence. Full details of this licence are available at: https://creativecommons.org/licenses/by-nc-nd/4.0/

\section{LICENCE}

CC BY-NC-ND 4.0

\section{REPOSITORY RECORD}

Mirgkizoudi, Maria, Changqing Liu, Paul P. Conway, and Steve Riches. 2019. "Mechanical and Electrical Characterisation of Au Wire Interconnects in Electronic Packages Under the Combined Vibration and Thermal Testing Conditions". figshare. https://hdl.handle.net/2134/16942. 


\section{Elsevier Editorial System(tm) for Microelectronics Reliability Manuscript Draft}

\section{Manuscript Number: MR-D-14-00621R1}

Title: Mechanical and electrical characterisation of Au wire interconnects in electronic packages under the combined vibration and thermal testing conditions

\section{Article Type: Research Paper}

Keywords: wire bonding, reliability testing, high temperature, vibration

Corresponding Author: Ms. Maria Mirgkizoudi, MSc

Corresponding Author's Institution: Loughborough University

First Author: Maria Mirgkizoudi, MSc

Order of Authors: Maria Mirgkizoudi, MSc; Changqing Liu; Paul Conway; Steve Riches

Abstract: This paper concerns the reliability of thermosonically bonded $25 \mu \mathrm{m}$ Au wires in the combined high temperature with vibration conditions, under which the tests have been carried out on wire bonded 40-pin Dual-in-Line (DIL) High Temperature Co-fired Ceramic (HTCC) electronic packages. Mechanical, optical and electrical analysis has been undertaken in order to identify the failure mechanisms of bonded wires due to the combined testing. The results indicated a decrease in the electrical resistance after a few hours of testing as a result of the annealing process of the Au wire during testing. Shear and pull strength levels remained high in general after testing, showing no significant deterioration due to the test under the combined high temperature and vibration conditions. However, a trend of the variation in the strength values is identified with respect to the combined conditions for all wire bonded packages, which may be summarised as: i) increase of the testing temperature has led to a decrease of both the shear and pull strength of the wire bonds; ii) the mechanical behaviour of the wires is affected due to crystallization that leads to material softening and consequently the deformation of wire. 


\title{
Mechanical and electrical characterisation of Au wire interconnects in electronic packages under the combined vibration and thermal testing conditions
}

\author{
M. Mirgkizoudi', C. Liu ${ }^{1}$, P.P. Conway ${ }^{1}$, S. Riches ${ }^{2}$
}

${ }^{1}$ Wolfson School of Mechanical and Manufacturing Engineering, Loughborough University, Loughborough, LE11 3TU, UK

${ }^{2}$ GE Aviation Systems-Newmarket, 351 Exning Road, Newmarket, Suffolk, CB8 0AU, UK

Corresponding author: Tel.: +44 (0) 1509227567

E-mail address: M.Mirgkizoudi@lboro.ac.uk

\section{ABSTRACT}

This paper concerns the reliability of thermosonically bonded $25 \mu \mathrm{m}$ Au wires in the combined high temperature with vibration conditions, under which the tests have been carried out on wire-bonded 48-pin Dual-in-Line (DIL) High Temperature Co-fired Ceramic (HTCC) electronic packages. Mechanical, optical and electrical analysis has been undertaken in order to identify the failure mechanisms of bonded wires due to the combined testing. The results indicated a decrease in the electrical resistance after a few hours of testing as a result of the annealing process of the Au wire during testing. In general, ball shear and wire pull strength levels remained high after testing, showing no significant deterioration due to the tests under the combined high temperature and vibration conditions. However, a trend of the variation in the strength values is identified with respect to the combined conditions for all wire-bonded packages, which may be summarised as: i) increase of the testing temperature has led to a decrease of both the shear and pull strength of the wire bonds; ii) the mechanical behaviour of the wires is affected due to crystallization that leads to material softening and consequently the deformation of wire.

Key words: wire bonding, reliability testing, high temperature, vibration. 


\section{Introduction}

Wire bonding in microelectronic packages has been used in industry for more than 60 years. Since the world's first wire bond was made in 1947, the number of wire bonds has increased every year [1]. In 2010, the wire bonding market-share for IC packaging was more than $85 \%$ ( 192.2 billion wire bonded devices). The extensive use of wire bonding lies on its advantages: 1) increased yields ( $<25$ ppm defects), 2) decreased pitch ( $20 \mu \mathrm{m}$ for both wedge and ball bonds), and 3) low process cost [1]. A variety of pure and alloy materials are used in wire bonding [2]. These materials are mainly, Au for ball bonding, and $\mathrm{Al}$ for wedge bonding, typically bonded on $\mathrm{Au}$ and $\mathrm{Al}$ bond pads. However, due to the high price of $\mathrm{Au}$, efforts are being made to replace $\mathrm{Au}$ with $\mathrm{Cu}$. In aerospace and oil \& gas applications, the wire bonded devices are subjected to a variety of loading conditions and most of the times to a combination of them. For instance, the temperature levels experienced in such applications can be up to $400^{\circ} \mathrm{C}$ and vibration excitation with frequencies up to $2000 \mathrm{~Hz}$ and acceleration up to $20 \mathrm{G}_{\mathrm{rms}}$.

The reliability of wire-bonded electronic devices has been thoroughly investigated. The main research focus is placed on the failures occurring during thermal cycling and high temperature endurance. The reliability of $\mathrm{Au}-\mathrm{Al}$ metallurgical systems has been studied extensively. These systems have been proven to be unstable due to intermetallics growth and subsequent voids formation within a few hours of thermal ageing at $175^{\circ} \mathrm{C}-200^{\circ} \mathrm{C}$ which causes mechanical weakness of the bonds [3][4]. On the other hand, research on the performance of $\mathrm{Au}$ wire-bonds on $\mathrm{Au}$ bond pad metallization has shown that these systems are more reliable due to a more stable interface between the bond and the bond pad metallization. Furthermore, the bond is not susceptible to interface corrosion or other bonddegrading conditions. Shepherd et al. [5] examined the changes in bond mechanical behaviour and the underlying microstructural stability of Au-Au metallurgical systems under 
thermal ageing at $250^{\circ} \mathrm{C}$ and $300^{\circ} \mathrm{C}$. They reported that these systems are mechanically robust in extreme environments with a stable microstructure.

In addition to problems caused by thermal exposure, electronic systems often experience vibration environments at the same time. In order to assure the long term reliability of components, the effects of vibration in combination with high temperature exposure conditions need to be investigated. However, separate environmental tests are commonly employed in qualification testing by the electronics industry, but are unable to reveal the effects of the combined conditions in terms of the failure modes and reliability. Therefore, the development of guidelines and testing standards is necessary to qualify electronic components that are required to operate in combined high temperature and vibration conditions.

Initial work has been reported by the authors to understand the effects of combined vibration and thermal loadings on wire bonded electronic devices in order to assist to the understanding of the significant degradation due to the combined testing conditions [6][7][8]. Bending and distortion of wires was found to be the main failure mode as observed in the experiments. Some fractures at the bonding interfaces between the chip and substrate were also taking place. The interfacial failure at the wire-bonds, and subsequently lift-offs was found mostly on the interconnections with the substrate. Our previous work [7] on the behaviour of the wire-bonded devices with respect to the direction of the vibration has also indicated that the distortion and subsequent failure is more severe when the wires are vertically oriented to the direction of the vibration. Failure modes such as wire lift-offs and short circuits occurred more often in such a case. It has also been proven that the wire loop formation is affected by the combined testing. The distortion of the wires was mostly found under low frequency vibration and high temperatures [8]. 
This paper reports a further investigation into the combined effects of temperature with vibration on $\mathrm{Au}$ wire-bonded interconnects used in the production of high temperature electronic components. The study is focused on the reliability testing of Au wire-bonds on $\mathrm{Au}$ bond pad metallization (hereafter refer to as $\mathrm{Au}-\mathrm{Au}$ system) under the combination of temperature exposure up to $250^{\circ} \mathrm{C}$ and vibration loading with the sine frequency swept cycles ranging from $5 \mathrm{~Hz}$ to $2000 \mathrm{~Hz}$ and acceleration up to $20 \mathrm{G}_{\mathrm{rms}}$. The wire-bonded $\mathrm{Au}-\mathrm{Au}$ system has been chosen due to its promise as a reliable solution in harsh environments. This work aims to elaborate the fundamental aspects of $\mathrm{Au}-\mathrm{Au}$ wire-bonds and their failure mechanisms by investigating the mechanical and electrical performance of the wire-bond interconnections where the effect of wire loop characteristics under separate and combined vibration and temperature storage tests has also been investigated.

\section{Experimental details}

\subsection{Wire Bonding}

The 48-pin Dual-in-Line (DIL) High Temperature Co-fired Ceramic (HTCC) devices, as seen in Figure 1, were tested in this study. The devices were thermosonically bonded by employing a K\&S 4500 semi-automatic wire bonder, using $99.9 \%$ pure Au wires of $25 \mu \mathrm{m}$ in diameter onto Au metallised bond pads. Ball-wedge bonding was performed by applying two bonding profiles in order to investigate how the loop geometry is affected by the applied testing conditions; one profile where the wires are forming a small loop and one larger (see Figure 2 for the bonding profile). The bonding parameters were optimized and provided in Table 1. 


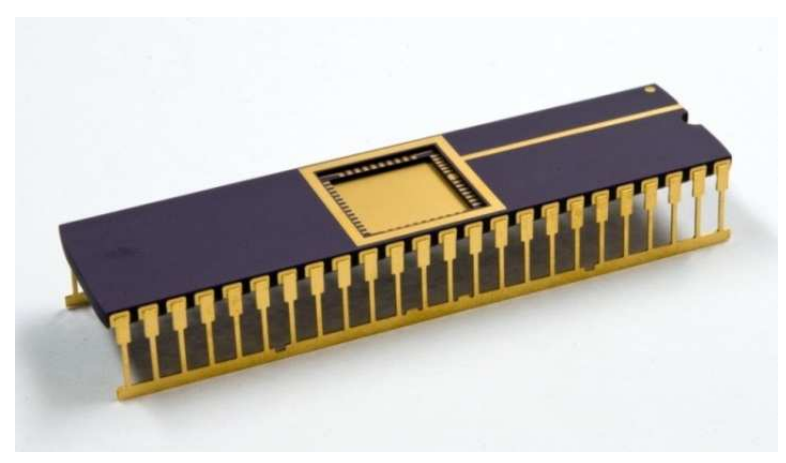

a)

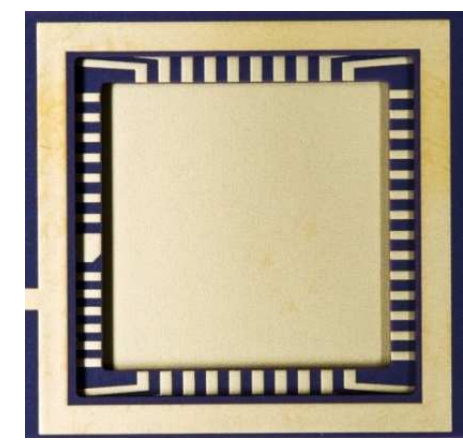

b)

Figure 1. Au/Ni 48-pin DIL HTCC test package, a) side view and, b) bonding area

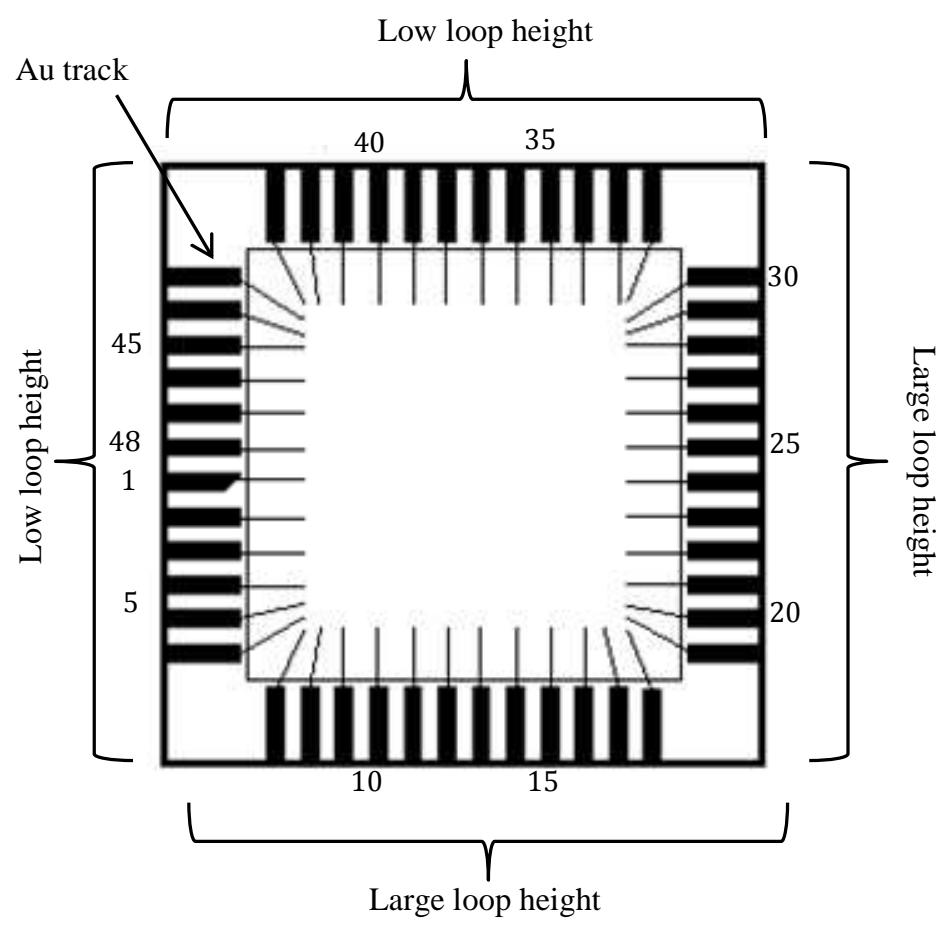

Figure 2. Schematic representation of the wire bonding profile 
Table 1. Wire bonding process parameters

\begin{tabular}{|c|c|c|c|c|c|}
\hline & Description & Small Loop & Large Loop & Ball Size & $\begin{array}{c}\text { Bonding } \\
\text { Temperature } \\
\end{array}$ \\
\hline & Time (ms) & 74 & 78 & \multirow{7}{*}{$75 \mu \mathrm{m}$} & \multirow{7}{*}{$120^{\circ} \mathrm{C}$} \\
\hline \multirow[t]{3}{*}{ Ball bond } & Power (W) & 1.42 & 1.42 & & \\
\hline & Force $(g(f))$ & 25 & 31 & & \\
\hline & Time (ms) & 110 & 114 & & \\
\hline \multirow[t]{2}{*}{ Wedge bond } & Power $(\mathrm{W})$ & 1.5 & 1.5 & & \\
\hline & Force $(g(f))$ & 85 & 89 & & \\
\hline Loop Height & $(\mu \mathrm{m})$ & 200 & 270 & & \\
\hline
\end{tabular}

\subsection{Combined High Temperature with Vibration Test Profile}

The packages have been subjected to combined high temperature with vibration testing under a sinusoidal vibration test profile along with the temperature set at $25^{\circ} \mathrm{C}, 180^{\circ} \mathrm{C}$, and $250^{\circ} \mathrm{C}$ in an open environment and without being hermetically sealed during testing. Constant heating at the aforementioned temperature levels was applied at the beginning of each test until the required levels have been reached, after which the vibration profile was introduced in the testing profile. The vibration test profile and parameters were based on guidelines and test procedures that are used for qualification of airborne equipment, e.g. the RTCA Aviation Standard DO-160E [9] which was applied along with thermal loading at the aforementioned temperature levels. The motion of the vibration shaker head was vertical and in this work it was assumed that this motion was on the $y$ axis of a three-dimensional Cartesian coordinate system, hence, the axis of vibration was the $y$ axis (see Figure 3). According to industry guidelines, electronics equipment should be tested in each of the equipment's three orthogonal axes (three orientations) [9]. For the purposes of this work, those three orientations (orientations 1, 2, and 3 in Figure 3) were related to the axis of the vibration in order to identify the effect of the orientation of the wires on the vibration system. Therefore, the combined tests replicated three times i.e. one time for each of the equipment's orthogonal 
axes. The duration of each test was 3 hours (one hour per axis). Sine frequency sweep cycles were performed varying the vibration frequency from the lowest $(5 \mathrm{~Hz})$ to the highest $(2000$ $\mathrm{Hz}$ ) (up-sweep) to the lowest (down-sweep) with a logarithmic rate not exceeding $1.0 \mathrm{oct} / \mathrm{min}$. The acceleration was varying from $1 \mathrm{~g}-\mathrm{PK}$ to $20 \mathrm{~g}-\mathrm{PK}$ with the amplitude between 0.0001 to 0.1 inches (peak-to-peak). The sinusoidal vibration test curve is given in Figure 4.

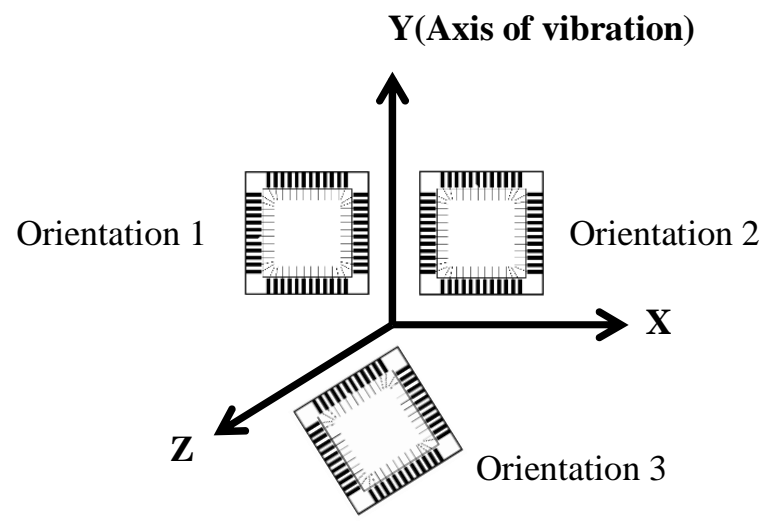

Figure 3. Sample orientation in respect to the axis of the vibration

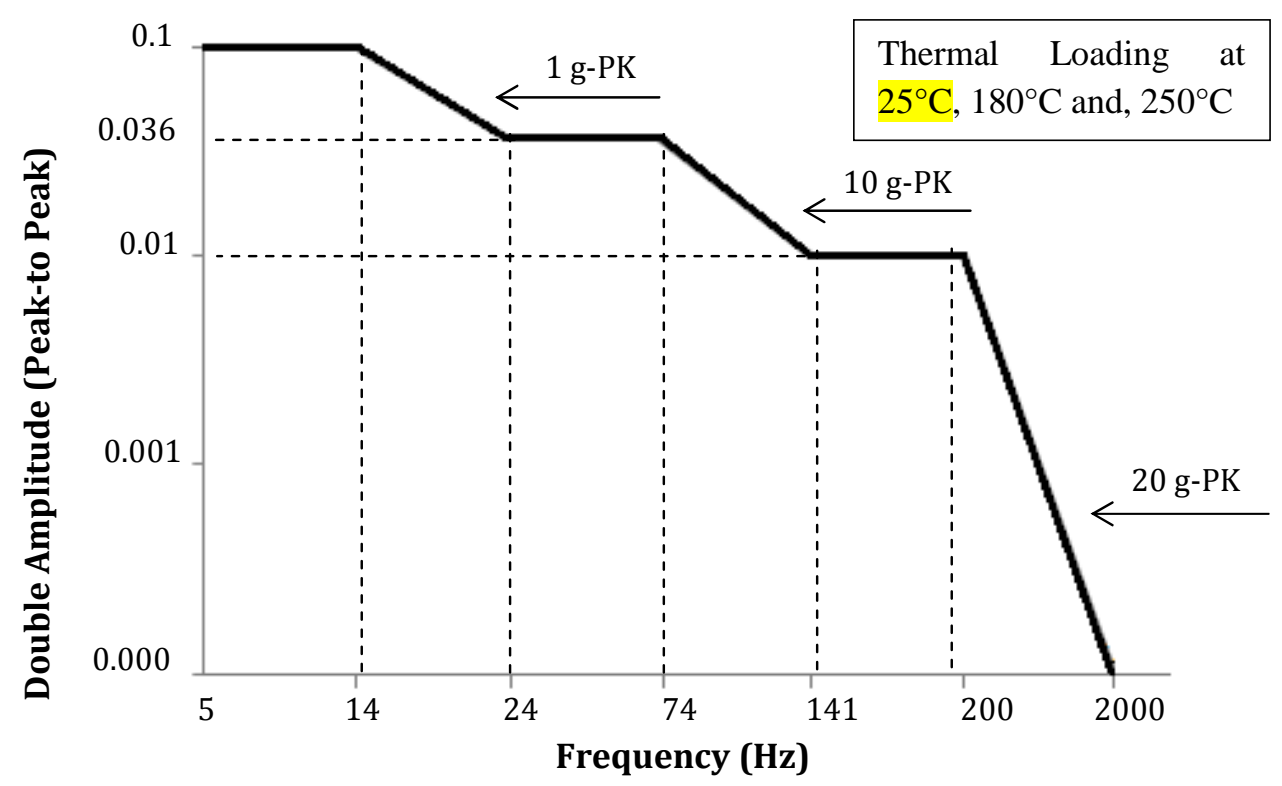

Figure 4. Sinusoidal vibration test curve 
An LDS V650 electro-dynamic shaker has been employed for the vibration testing. The vibration test profile was designed and applied using the $m+p$ VibControl vibration controller and software. A specially designed hot plate was mounted on the shaker head for the heat-up of samples which were fixed on the hot plate. A thermocouple, which was attached on the hot plate close to test samples, were utilised to control the temperature. Accelerometers were fixed on the hot plate close to the wire-bonded devices to measure the input signal.

\subsection{Post Testing Characterisation}

The mechanical strength of the wire bonds was evaluated by means of ball shear and wire pull strength measurements with the ball shear test speed at $200 \mu \mathrm{m} / \mathrm{s}$ and the wire pull test speed set at $100 \mu \mathrm{m} / \mathrm{s}$. One sample was used per characterisation method, therefore, forty-eight wires have been tested for the shear strength measurements and forty-four for the wire pull strength measurements. Due to the design of the bonding area, testing of the wire pull strength of the wires located at the four corners of the bonding area proved difficult as it was observed that positioning and rotation of the tool under those wires would damage the neighbouring wires thus, forty-four instead of forty-eight wires were tested for their wire pull strength. The electrical resistance values were recorded before and after each test by employing a 4-point probe measurement system with the test current set at $10 \mathrm{~mA}$. Finally, the mechanical deformation of the wires was observed by means of optical microscopy with the magnification varying from $\mathrm{x} 5$ to $\mathrm{x} 100$.

\section{Experimental Results}

\subsection{Effects of High Temperature with Vibration Test on the Mechanical Strength of the} Bonded Wires

Figures 5 and 6 are the mechanical test results of ball shear and wire pull strength respectively. The mechanical tests were conducted after the wire bonded devices have been 
tested under the three different combinations of testing conditions, i.e. - vibration test at $25^{\circ} \mathrm{C}$, $180^{\circ} \mathrm{C}$ and $250^{\circ} \mathrm{C}$. Table 2 presents the average values for the ball shear and wire pull strength levels.

Figure 5 shows the ball shear test results for all the bonds included in the package under the three testing conditions. Accordingly, an obvious trend can be observed with respect to the effects of testing temperature along with the vibration parameters. After the vibration test at $25^{\circ} \mathrm{C}$ the ball shear strength for both loop profiles remained high. In this case, the bonds of the large loop profile showed a higher average value however the large standard deviation of 10.6 shows large spread of the individual results of each bond. It is therefore believed that, despite their lower average value, the bonds of the small loop profile performed better than those of the large profile by having a more consistent ball bond strength.

Deterioration of the ball shear strength was recorded after introducing thermal loading $\left(180^{\circ} \mathrm{C}\right)$ to the vibration excitation. The ball shear strength for both loop profiles reduced significantly especially for the ball bonds of the large loop profile. In this case of the large loop wires, five out of twenty-four ball bonds failed to exceed the industry's minimum value of $30 \mathrm{~g}(\mathrm{f})$ [10] with the rest of the bonds having ball shear strengths very close to the minimum value.

Weak performance was recorded for the ball bonds tested under vibration at $250^{\circ} \mathrm{C}$. Both loop profiles had ball bonds that failed to exceed the minimum value of $30 \mathrm{~g}(\mathrm{f})$. The largest number of failed ball bonds was recorded for the large loop profile where fifteen out of twenty-four ball bonds failing. 


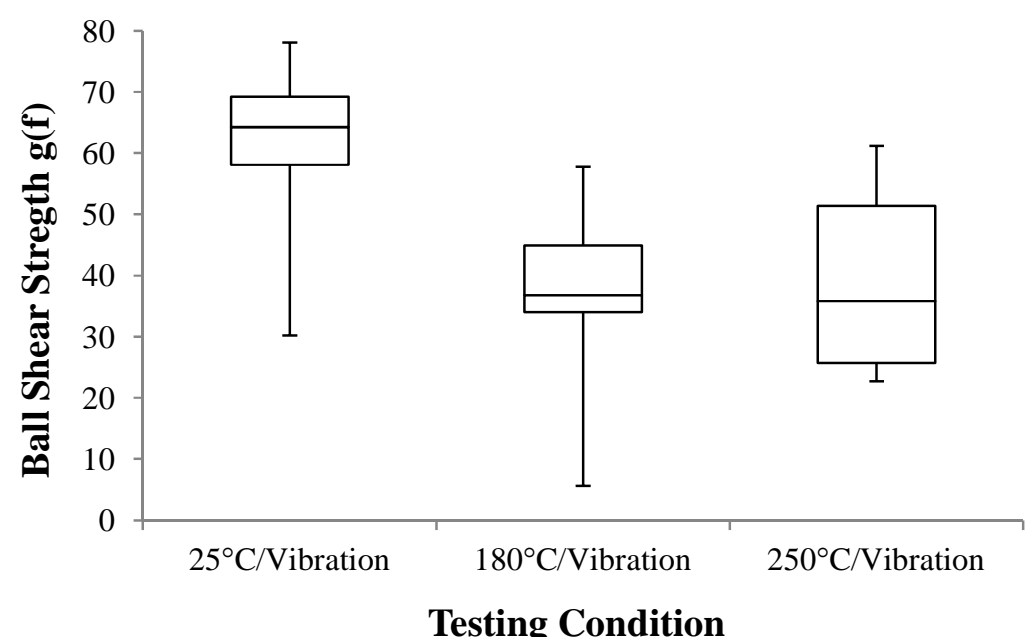

Figure 5. Ball shear strength values of ball bonds after vibration test at $25^{\circ} \mathrm{C}, 180^{\circ} \mathrm{C}$ and $250^{\circ} \mathrm{C}$

The recorded wire pull strength levels for the three testing conditions are displayed in Figure 6. All the bond pull strength levels of the wires for both bonding profiles for all the testing conditions exceeded the military standard minimum of $3 \mathrm{~g}(\mathrm{f})$ [11], although, similarly to the shear strength results, the average wire pull strength levels decreased with increasing temperature. It is believed that the decrease in the wire pull strength is associated with a decrease in the yield strength of the wire. Decrease in the yield strength may lead to mechanical softening of the wires which could explain the low pull force values.

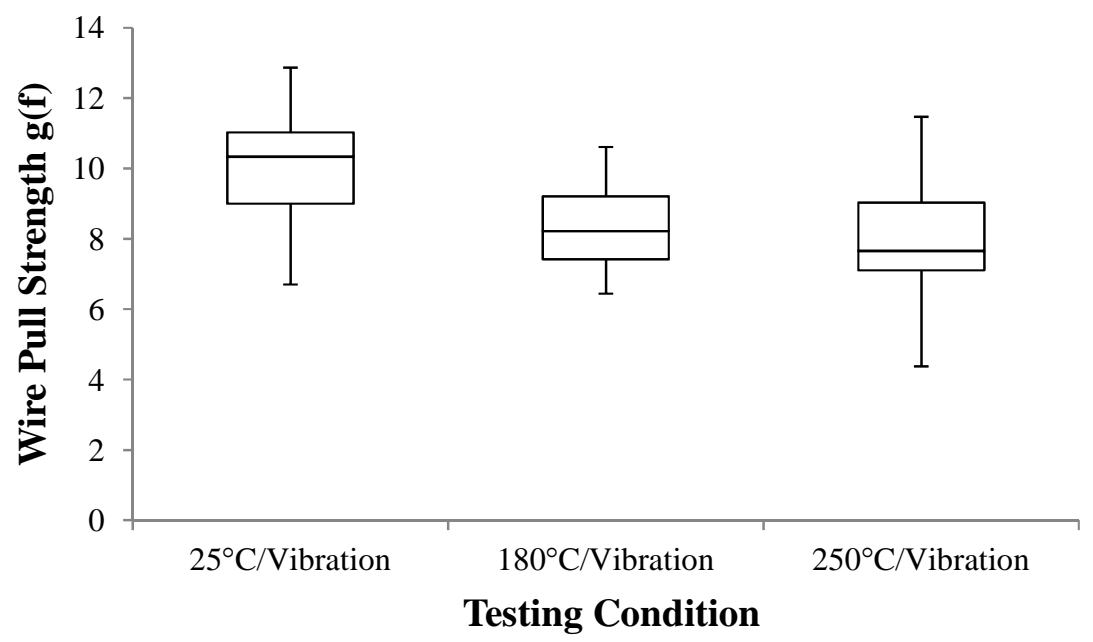

Figure 6. Wire pull strength values of wires after vibration test at $25^{\circ} \mathrm{C}, 180^{\circ} \mathrm{C}$ and $250^{\circ} \mathrm{C}$ 
Table 2. Average ball shear and wire pull strength levels for $\mathrm{Au}$ wires

\begin{tabular}{|c|c|c|c|c|c|}
\hline & Unit & As-bonded & $25^{\circ} \mathrm{C} /$ Vibration & $180^{\circ} \mathrm{C} /$ Vibration & $250^{\circ} \mathrm{C} /$ Vibration \\
\hline Ball Shear & \multirow{2}{*}{$g(f)$} & 71.62 & 63.92 & 39.05 & 39.04 \\
\hline Wire Pull & & 10.42 & 10.02 & 8.35 & 7.9 \\
\hline
\end{tabular}

3.2. Effect of High Temperature with Vibration Test on the electrical resistance of the Bonded Wires

The electrical resistance of the wire bonded packages was measured before and after the combined high temperature with vibration tests between two adjacent pins on the test package which includes two wires and the associated tracking as it can be seen from the Xray image that shows the tracks buried inside the package in Figure 7a. A 4-probe measurement system has been used for the assessment of the electrical resistance. The connector cables that were used for the electrical resistance measurements (Figure $7 \mathrm{~b}$ ) were connected to a micro-ohmmeter.

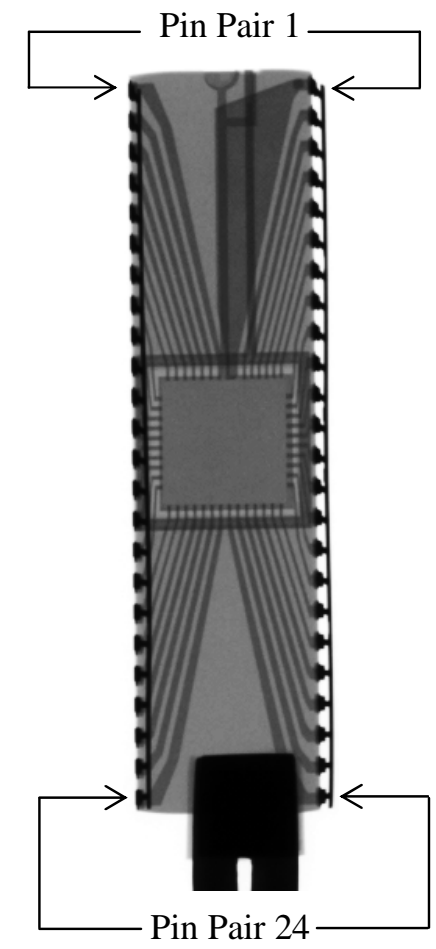

a)

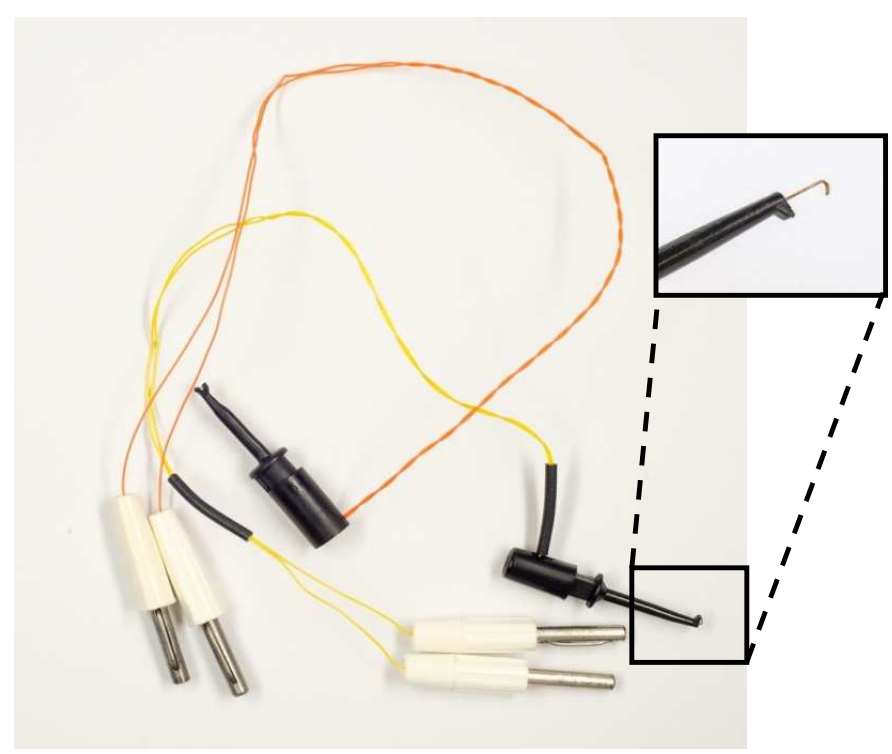

b)

Figure 7. X-ray image of 48-pin DIL-HTCC package. The tracks inside the package provide connection between the pins and the bond pad 
For the vibration tests at $25^{\circ} \mathrm{C}, 180^{\circ} \mathrm{C}$ and $250^{\circ} \mathrm{C}$ for 3 hours an unexpected initial electrical resistance decrease has been observed for all the samples tested under those conditions compared to the values obtained from the as-bonded samples. Thus, it has been decided to extend the duration of the testing regime to 9 hours in total and also to include temperature storage tests at $180^{\circ} \mathrm{C}$ and $250^{\circ} \mathrm{C}$ in the testing protocol in order to gain a better understanding of the electrical performance of the wire bonded devices. Figures 8 through 12 include the electrical resistance test results for the initial and extended test profiles. The percentage of the average electrical resistance change is depicted as a function of time.

The graph in Figure 8 shows the percentage of the average electrical resistance change of the sample tested under vibration at $25^{\circ} \mathrm{C}$ for 3,6 and 9 hours. For the first 3 hours of testing the average electrical resistance decreased by $-1.5 \%$ from the initial value. Further decrease ($1.07 \%$ ) has been recorded after the sample has been subjected to further 3 hours of testing (6 hours in total). Finally, after testing for 9 hours in total, the resistance increased by approximately $1 \%$ compared to the previously recorded value.

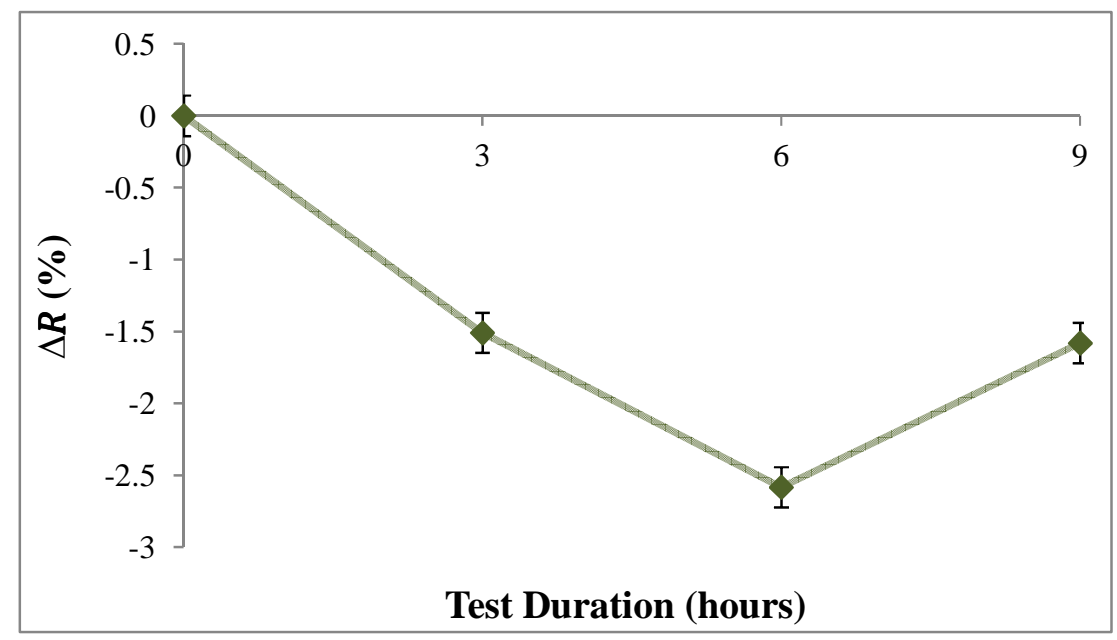

Figure 8. Percentage of resistance change for the sample tested under vibration for $3 \mathrm{~h}, 6 \mathrm{~h}$ and 9h.

Similar electrical performance has been observed for the sample tested under vibration at $180^{\circ} \mathrm{C}$ as seen in Figure 9. Introducing temperature to the vibration regime resulted to 
relatively larger decrease $(-1.51 \%)$ of the average resistance after 3 hours of testing compared to the vibration test at $25^{\circ} \mathrm{C}(-1.5 \%)$. Further decrease $(-1.12 \%)$ has been observed after 6 hours of testing in total. Finally, the average resistance increased by $1.13 \%$ after 9 hours.

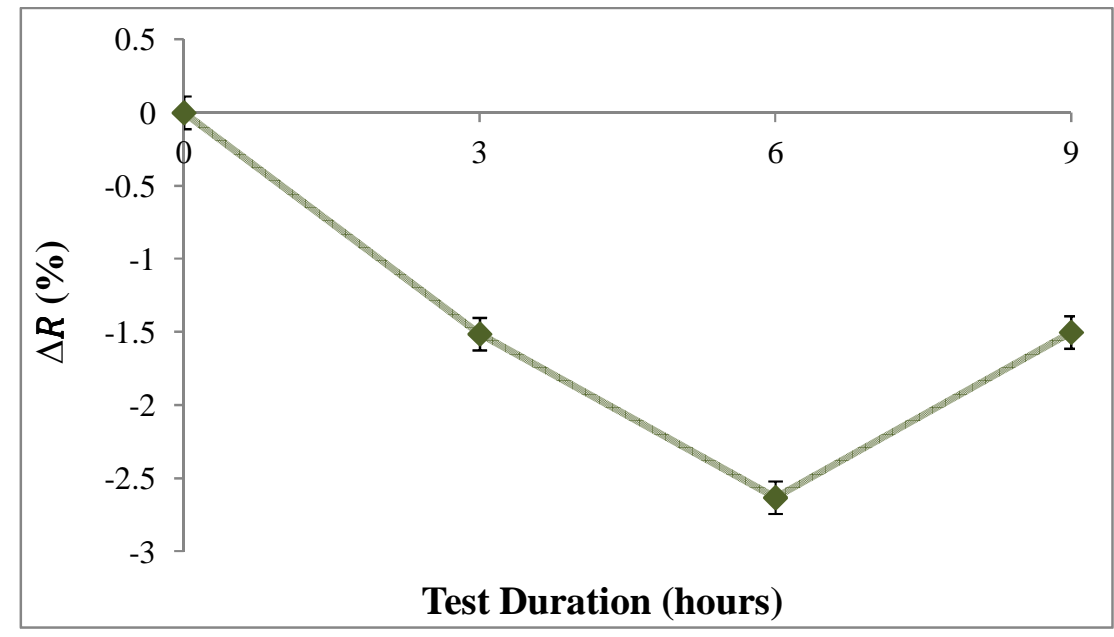

Figure 9. Percentage of resistance change for the sample tested under vibration at $180^{\circ} \mathrm{C}$ for $3 \mathrm{~h}, 6 \mathrm{~h}$ and $9 \mathrm{~h}$.

Figure 10 shows the percentage of the electrical resistance change for the sample tested under vibration at $250^{\circ} \mathrm{C}$ for 3,6 and 9 hours. A slightly larger electrical resistance decrease $(-1.52 \%)$ was recorded after the first 3 hours of testing compared to the results from the sample tested under vibration at $180^{\circ} \mathrm{C}$. Further decrease of $-1.12 \%$ was recorded after 6 hours of testing and an increase of $1.8 \%$ after 9 hours of testing. 


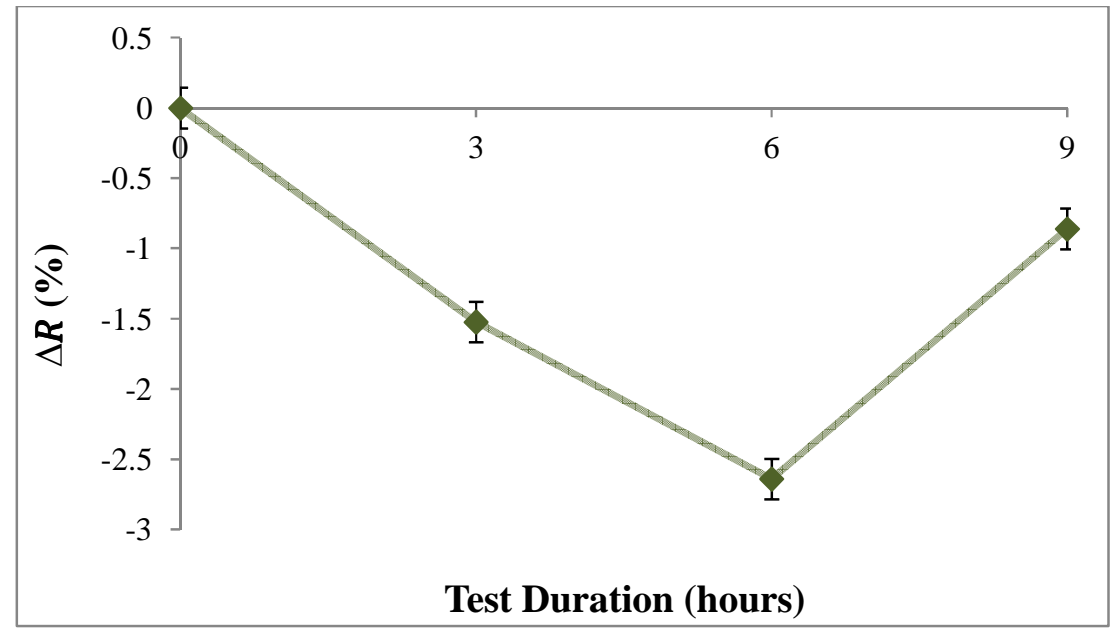

Figure 10. Percentage of resistance change for the sample tested under vibration at $250^{\circ} \mathrm{C}$ for $3 \mathrm{~h}, 6 \mathrm{~h}$ and $9 \mathrm{~h}$

As previously mentioned, the testing profile has been extended to include the electrical resistance results after temperature storage of the wire bonded devices at $180^{\circ} \mathrm{C}$ and $250^{\circ} \mathrm{C}$ for 3, 6 and 9 hours in order to reveal the effects of temperature as a single loading condition and compare the results with those from the combined testing. Figures 11 and 12 show the percentage of the average electrical resistance change for the two aforementioned testing conditions. After temperature storage at $180^{\circ} \mathrm{C}$ (Figure 11) for 3 hours the average electrical resistance decreased by $-1.36 \%$. Increase of the average resistance by $0.27 \%$ was recorded after 6 hours of testing and further increase of $0.9 \%$ after 9 hours of testing. In the case of temperature storage at $250^{\circ} \mathrm{C}$ (Figure 12) for the first 3 hours, the resistance decreased by $-0.7 \%$ with a further decrease of $-0.4 \%$ after 6 hours. Finally, after 9 hours of testing and increase of $1.7 \%$ has been recorded. 


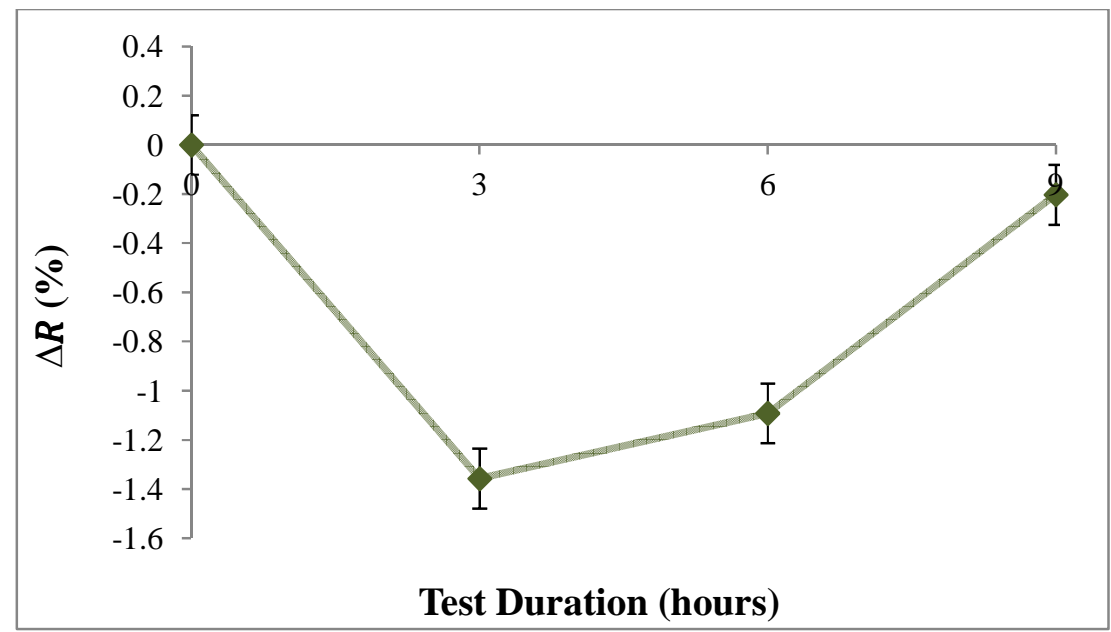

Figure 11. Percentage of resistance change for the sample tested at $180^{\circ} \mathrm{C}$ for $3 \mathrm{~h}, 6 \mathrm{~h}$ and $9 \mathrm{~h}$

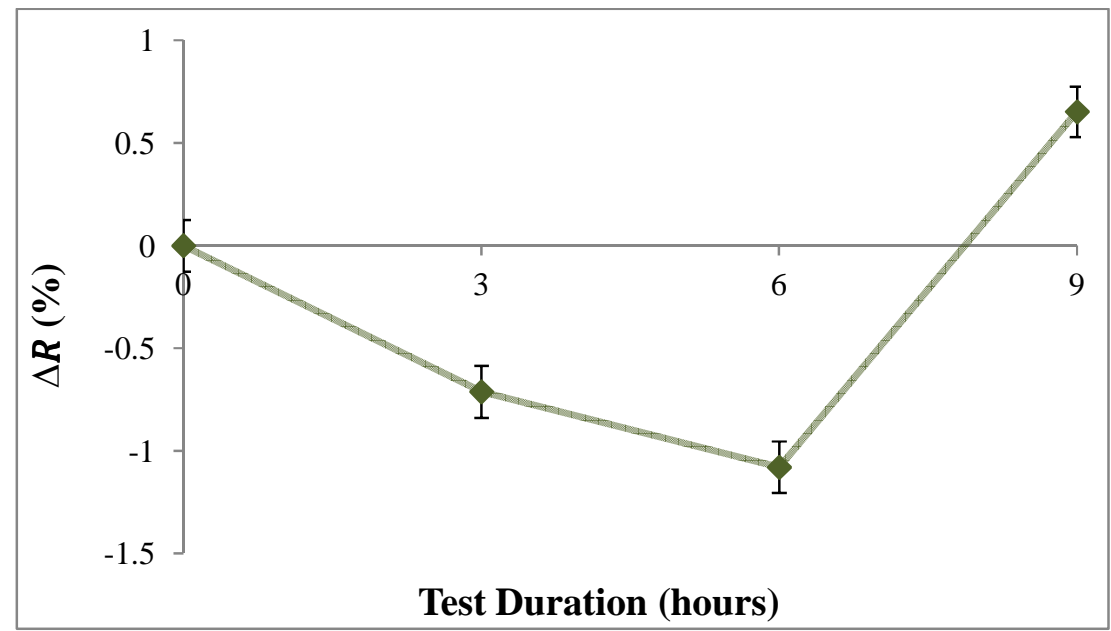

Figure 12. Percentage of resistance change for the sample tested at $250^{\circ} \mathrm{C}$ for $3 \mathrm{~h}, 6 \mathrm{~h}$ and $9 \mathrm{~h}$.

\subsection{Mechanical Deformation of Bonded Wires due to High Temperature with Vibration Testing}

Visual inspection has been performed to identify any wire deformation or distortion that has been induced by the applied testing conditions. As reported previously [6], [7], [8], the orientation of the wires in respect to the axis of the vibration, results in different failure modes.

In the case of the vibration test at $25^{\circ} \mathrm{C}$ specific wire deformation patterns have been identified. While the majority of the wires remained intact after testing, two failure modes 
were observed. Both failure modes are associated with changes in the loop characteristics. First, the wire loop collapsed sideways causing the loop height to reduce and the wire to deform. Wires that were vertically oriented in respect to the direction of the vibration were deformed following one direction (Figure 13a). Testing on the other two axes had the same effect on some of the wires but no particular pattern of deformation was observed. Second, the wire loop collapsed downwards (towards the Au pad). This phenomenon had two different effects i.e. the collapse caused the wires to touch the edge of the Au bonding area causing short circuiting (Figure 13b), phenomenon that mostly observed at the large loop wires, and also the wires appeared sharply curved (kinked) at the highest point of the loop (Figure 13c). The phenomenon mostly observed at the small loop wires.
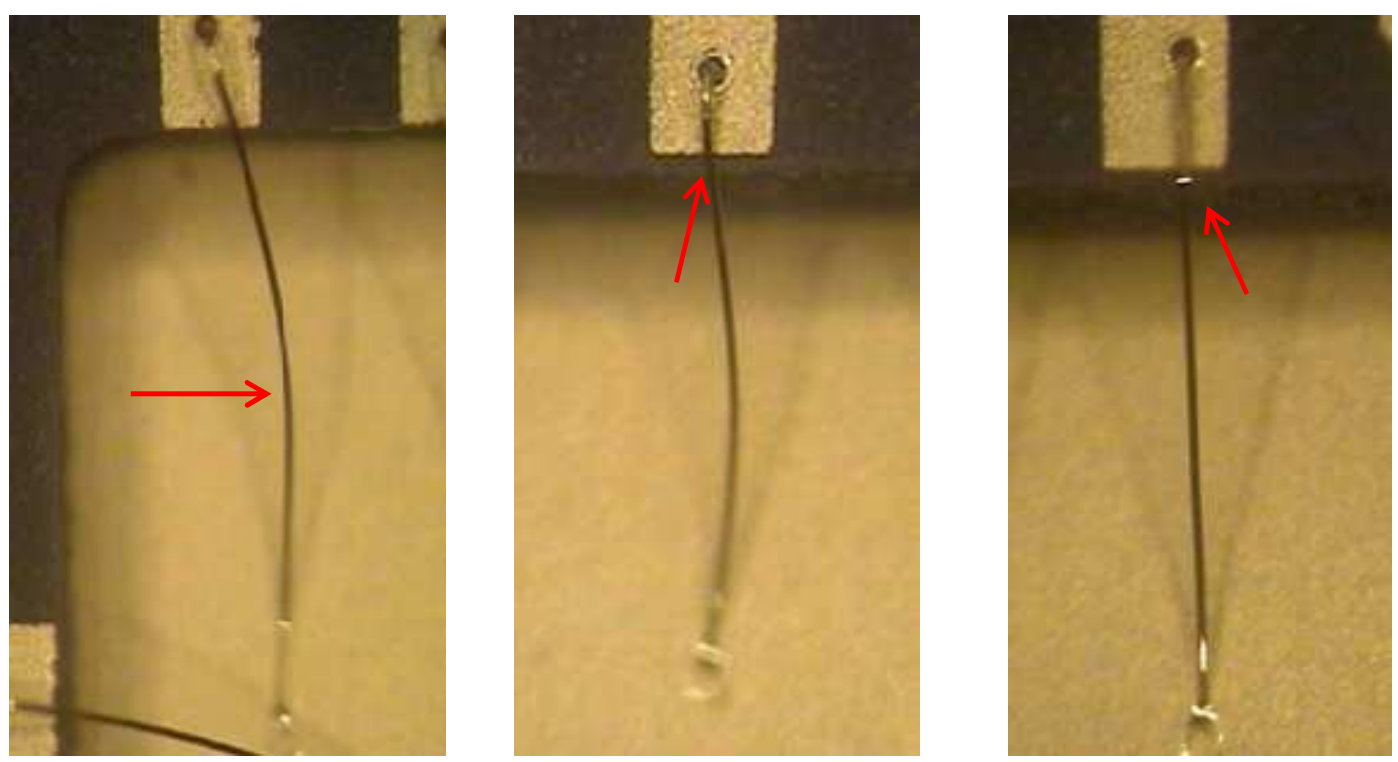

Figure 13. Wire deformation, loop collapsed a) sideways following one direction and, loop collapsed downwards where a) the wire touched the Au bonding area and b) the wire was sharply curved after testing

Figure 14 shows a deformed wire after the vibration test at $180^{\circ} \mathrm{C}$. The wire loop collapsed sideways and, in addition to this phenomenon, the wire appeared kinked at the highest point of the loop. This phenomenon occurred on one of the wires that were vertically 
oriented towards the direction of the vibration. It is clear that the deformation caused in a vibration environment can be accelerated by temperature related effects.

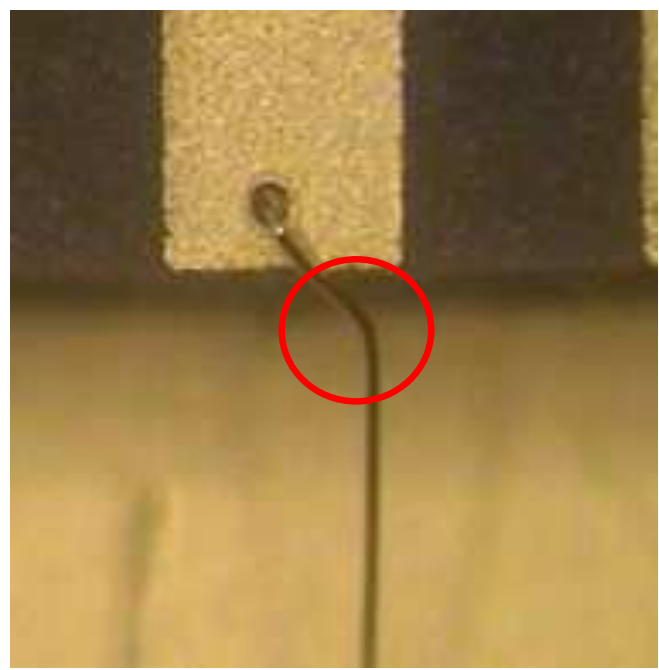

Figure 14. Sharply curved and deformed wire after combined testing.

The most severe deformation occurred by the vibration test at $250^{\circ} \mathrm{C}$. The same failure modes that were identified from the vibration testing at $25^{\circ} \mathrm{C}$ could also be seen in this case. As it was explained above, temperature can accelerate the deformation caused in a vibration environment. As seen in Figure 15, the majority of the wires were severely deformed following again specific deformation patterns. Figure 15a shows the deformation for the large loop wires. These particular wires were parallel to the direction of the vibration while testing. As it was observed before, while testing on this direction, the wire deformation is random and the loop collapses sideways either left or right from the initial wire position. Deformation following one particular direction occurred for the wires that where vertically oriented to the direction of the vibration. An example can be seen in Fig. 15b. Finally, wire deformation occurred not only at the highest point of the wire loop but near the wedge bond as well, as indicated in Fig. 15c. Table 3 presents the quantitative results of the failure modes and percentages of their appearance for the Au-Au system. 


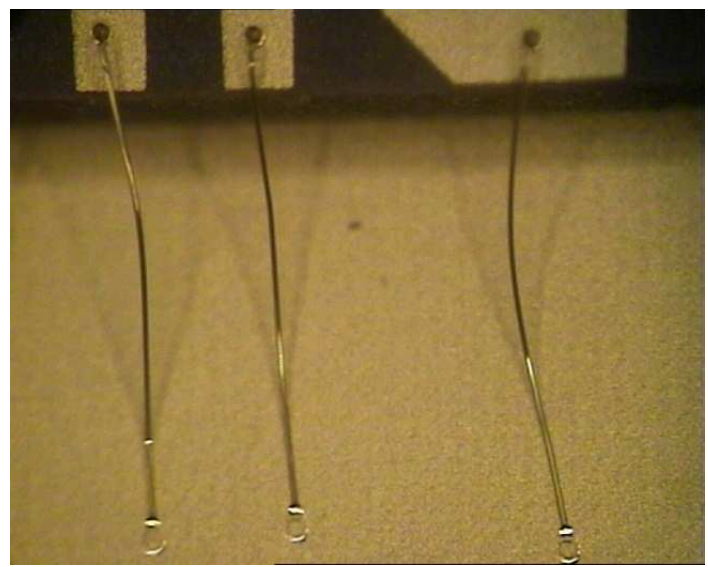

a)

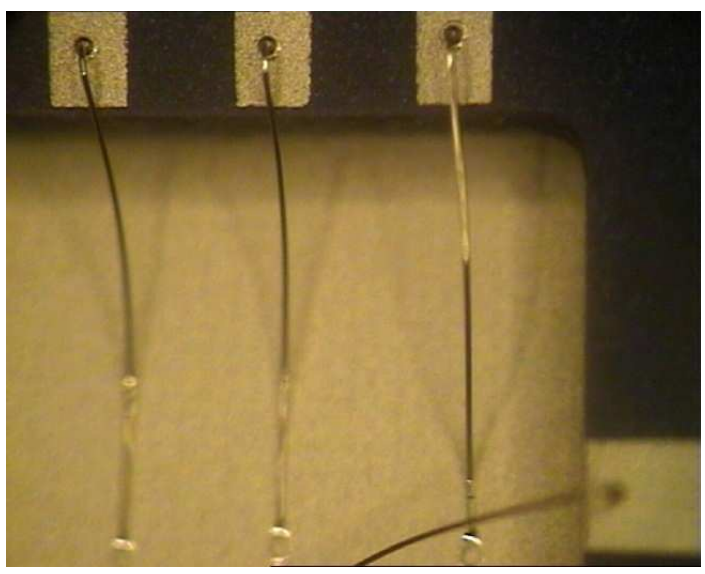

b)

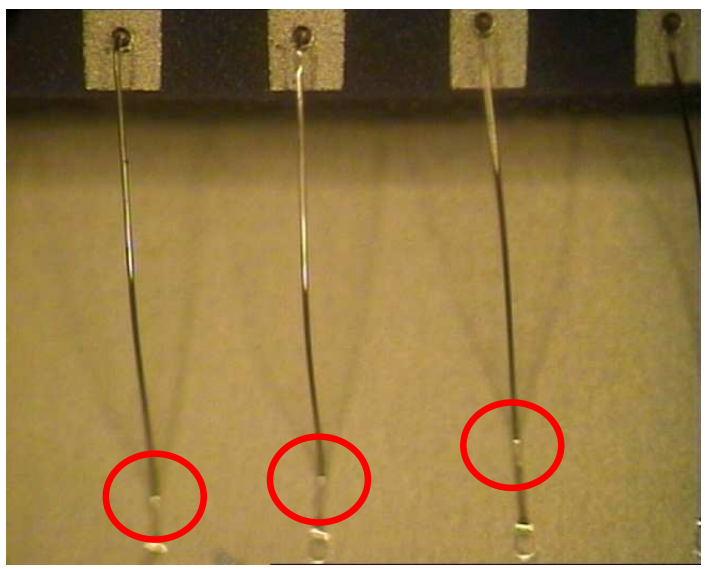

c)

Figure 15. Wire deformation from testing a) on vibration axis, b) on axis vertical to direction of vibration and, c) sharply curved wires close to wedge bond 
Table 3. Wire loop failure modes and deformation of Au wires

\begin{tabular}{cc}
\hline \hline Failure Mode & Au-Au System \\
\hline \hline Kinked wires & $20.8 \%$ \\
Wire sweep & $33.3 \%$ \\
Collapsed loop & 41.6 \\
Broken Wires & 0 \\
Wire short & 0 \\
\hline
\end{tabular}

It is therefore concluded, based on the visual inspection of the wire bonded devices, that the orientation of the wires in respect to the direction of vibration plays an important role in the wire deformation. Thus, it is essential, when designing wire bonded devices, to take under consideration the vibration environment that they are serving and also measure the vibration response of those devices in those specific conditions. Also, another solution in order to avoid wire deformation could be to improve the mechanical properties of the $\mathrm{Au}$ wire by mechanical strengthening by impurity doping of $1 \% \mathrm{Si}$, for example [1].

\section{Discussion}

\subsection{Mechanical Strength of Bonds \& Wires}

Shepherd et al. [5] reported small deterioration of the ball shear and wire pull strength after long-term thermal ageing at $250^{\circ} \mathrm{C}$ with the ball shear and wire pull strength levels remaining high even after 2000 hours of testing. The low mechanical strength levels resulted from the combined tests in our work indicate the contribution-to-failure of the vibration effects to the temperature related effects. It is hypothesised that fatigue due to temperature applied and stresses caused on the wire bonds due to the vibration loading could be the main reasons for such a significant reduction of the mechanical strength levels. From visual inspection of the sheared ball bonds it was observed that the main failure mode was ball shear, i.e. a thin layer of the bonding surface metallization remained with the wire bond and an impression is left in the bonding surface. Apart from the temperature related effects that caused the structural weakening at the interface between the ball bond and the bond pad, the 
phenomenon is also believed to be associated with stresses applied to the bond due to vibration loading. Furthermore, a reduction in the wire yield strength is assumed to be associated with the low wire pull test results. Temperature associated effects were identified that led to mechanical softening of the wire and as a result most of the wires broke close to the highest point of the wire pull.

Furthermore, during the visual inspection of the wire and bond morphology after the wire pull tests, it has been observed that most of the wires broke immediately above the ball bond.

This could be explained by the grain structure of the wire at the zone above the ball bond. The grain sizes of a wire affect the properties of the wire, including its strength. During the Au ball wire bonding process, a spark is used to melt the tip of the wire and create the free-air ball which is then pressed against the bond pad to form the ball bond. The melting of the wire has as a result the formation of coarse grains due to the fact that heat causes larger grain sizes. As heat propagates to the wire it causes the grain size of the wire above the ball bond to increase too. This large grain area above the ball is also called heat-affected zone (HAZ). As the distance from the ball bond increases, the increase in the grain size diminishes due to less exposure to heat [1].

\subsection{Electrical Performance}

A general trend was identified in terms of the changes of the electrical resistance values for all the samples tested under the combined testing conditions and after thermal ageing. This trend was similar in both testing profiles i.e. combined testing and thermal ageing and it involved a decrease of the electrical resistance for the first 6 hours of exposure to the testing conditions and an increase for further 3 hours (9 hours in total). Only in the case of thermal ageing at $180^{\circ} \mathrm{C}$ the electrical resistance decreased for the first 3 hours then increased for further 6 hours of testing. Table 4 shows the change tendency of the measured electrical resistance varied with the testing parameters. The values depicted in the table are the 
percentage changes (increase $(+)$ or decrease $(-))$ that were recorded after each measurement was taken at 3, 6 and 9 hours of testing.

As it can be seen in Table 4, the combined conditions in all the three cases i.e. vibration test at room temperature, $180^{\circ} \mathrm{C}$ and $250^{\circ} \mathrm{C}$ for the first 6 hours of testing, had similar effect on the electrical resistance. For the first 3 hours the resistance decreased by approximately $1.5 \%$ for all the combined testing conditions and approximately $-1.1 \%$ for further 3 hours. Further combined testing up to 9 hours resulted in an increase of resistance which was more noticeable in the case of vibration test at $250^{\circ} \mathrm{C}$. It is hypothesised that during the first 6 hours of testing the wires and bonds underwent further annealing that may have changed the material properties of the wire and the bond i.e. decrease of electrical resistance. Furthermore, internal stresses at the interface between the ball bond and the bond pad may have affected the resistance change and resulted to an increase after the 6 hours of testing. The increase of the electrical resistance after 9 hours of testing, especially for the samples tested under vibration at $250^{\circ} \mathrm{C}$, indicates that those failures occurred during that period of time. Further investigation on the mechanisms that lead to an initial decrease of the electrical resistance is essential.

The contribution of vibration effect to the electrical performance of the wire bonded system is not yet fully understood. However, the results indicate that the change in the electrical resistance at high temperatures i.e. thermal ageing at $250^{\circ} \mathrm{C}$ follows the same pattern as after the vibration test at $250^{\circ} \mathrm{C}$. Therefore, the changes in electrical resistance are most likely temperature dependent and vibration has little or no effect on the electrical resistance however further investigation is required in order to gain a full understanding.

Table 4. Percentage changes of the electrical resistance varied with the testing parameters 


\begin{tabular}{cccccc}
\hline $\begin{array}{c}\text { Test } \\
\begin{array}{c}\text { Duration } \\
\text { (h) }\end{array}\end{array}$ & \multicolumn{5}{c}{ Testing Condition } \\
\hline \hline & $\begin{array}{c}\text { Vibration } \\
\text { at room } \\
\text { temp. }\end{array}$ & $\begin{array}{c}\text { Vibration } \\
\text { at } \mathbf{1 8 0}\end{array}$ & $\begin{array}{c}\text { Vibration } \\
\text { at 250 }\end{array}$ & $\begin{array}{c}\text { Thermal } \\
\text { ageing at } \\
\mathbf{1 8 0}^{\circ} \mathbf{C}\end{array}$ & $\begin{array}{c}\text { Thermal } \\
\text { ageing at } \\
\mathbf{2 5 0}\end{array}$ \\
\hline $\mathbf{3}$ & $-1.5 \%$ & $-1.51 \%$ & $-1.52 \%$ & $-1.36 \%$ & $-0.7 \%$ \\
\hline $\mathbf{6}$ & $-1.07 \%$ & $-1.12 \%$ & $-1.12 \%$ & $+0.27 \%$ & $-0.4 \%$ \\
\hline $\mathbf{9}$ & $+1 \%$ & $+1.13 \%$ & $+1.8 \%$ & $+0.9 \%$ & $+1.7 \%$ \\
\hline
\end{tabular}

It has to be noted that measuring the resistance changes of the wire bonds proved very challenging because of the large fluctuations that can occur in the interconnections between the wires and the package during testing. Therefore, in-situ measurements of the electrical resistance would be more favourable which can provide a better understanding on the way that the wire bonded interconnects behave electrically. However, in-situ measurements proved difficult due to the nature of the testing conditions i.e. high temperature and vibration, which did not allow any of the conventional measurement techniques to be applied.

\subsection{Mechanical Deformation of Bonding Wires}

Specific wire deformation patterns have been identified from the combined high temperature and vibration tests due to possible changes in the mechanical properties which can be accelerated by vibration induced fatigue of the wires. The theory on the response of electronic packages to vibration dictates that the most critical location for components mounted on an electronic device, and thus the most susceptible to failure, is at the centre of the device causing the most rapid changes of curvature that occur during the fundamental resonant frequency of the device [12]. The forces and stresses that are applied during vibration excitation are related to the relative curvature of the device during its resonant condition which is linked to the displacement of the device. If the component is placed away from the centre, then the degree of curvature is reduced and therefore the relative motion between the device and the components is also reduced as seen in Figure 16 [12]. In the case 
where the 48-pin HTCC-DIL packages the Au wires were located at the periphery of the centre of the package therefore their fatigue life is also related to the dynamic displacements developed during vibration.

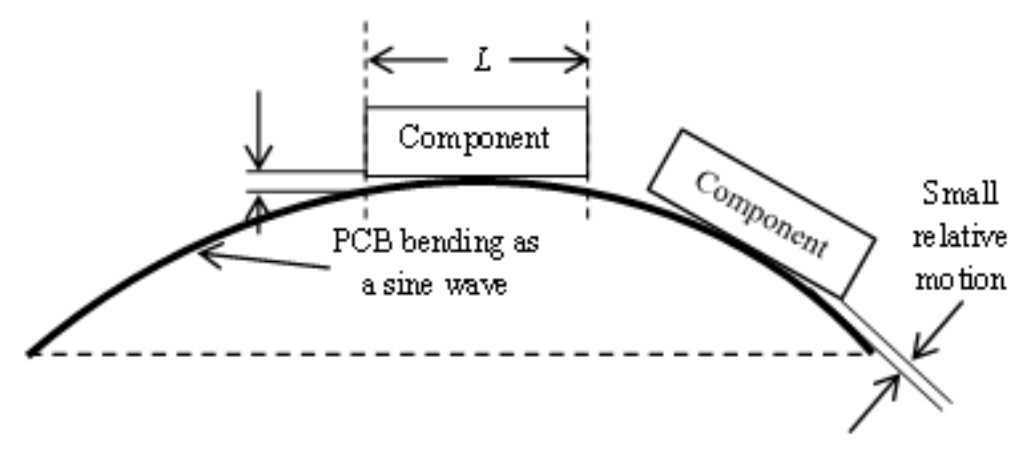

Figure 16. Relative motion between the component and the PCB is reduced when the component is mounted near the PCB edge [12]

It has been observed that specific deformation patterns occur based on the wire orientation in relation to the vibration direction. Particularly, the most vulnerable orientation for the wires is the one vertical to the direction of the vibration where wire sweep is often experienced. Wire sweep and wire sag are a common problem in wire-bonded devices which can be accelerated when large loop profiles are used, especially when small bond pitch and layer pitch is required [13]. Wire sweep is the lateral movement of the wire while wire sag is the downward deformation of the wire that can result to the wire touching the bond pad or substrate which can lead to wire shorting and failure of the IC [14]. The wire sweep that occurred during the combined high temperature with vibration testing was mostly found when testing on the axis vertical to the vibration direction at $250^{\circ} \mathrm{C}$.

In addition to the vibration related effects, wire softening caused by the temperature applied is also another factor that can explain the deformation of the wires. The loop characteristics (shape, height) of the Au wire are directly proportional to the mechanical characteristics of the HAZ above the ball bond; generally, the longer the HAZ, the higher the 
loop height [1]. The hardness values of the wire tends to decrease with the distance from the ball neck until it reaches a minimum value at around $166 \mu \mathrm{m}$, beyond which it rises rapidly until it reaches the hardness of the heat unaffected wire. The hardness dependence of the wire on the HAZ is directly connected to the grain size effect. The HAZ is the most susceptible part of the wire bond due to the large grain size in this region. As temperature is applied on the wire bond, the grain size increases therefore, the plastic properties, hence the hardness, at the HAZ deteriorate, also the hardness of the wire at the distance of $166 \mu \mathrm{m}$ resulting to a softer wire.

\section{Conclusions}

The combined effects of temperature and vibration on $\mathrm{Au}-\mathrm{Au}$ wire bonded metallurgical systems have been investigated. Sine frequency sweep cycles were performed with the vibration frequency varying from $5 \mathrm{~Hz}$ to $2000 \mathrm{~Hz}$, along with thermal loading at three different levels $\left(25^{\circ} \mathrm{C}, 180^{\circ} \mathrm{C}, 250^{\circ} \mathrm{C}\right)$. The results can be summarised as follows:

1. A reduction in the ball shear failure strength has been observed from the ball shear tests of test wire bonds. $43.75 \%$ of the bonds failed to exceed the industry's minimum of 30 $g(f)$ after the vibration test at $250^{\circ} \mathrm{C}$. Nevertheless, the wire pull strength levels remained high in all the cases with a clear trend in respect to the temperature rise; the average wire pull strength decreases with increasing temperature. Furthermore, the lowest strength levels have been observed in the case of the large loop wire profile.

2. Fluctuations of the recorded electrical resistance values of the bonded wires after high temperature with vibration testing have been found, which is likely attributed to the deformation and microstructural evolution of the wires due to testing. For all the combined testing conditions, the electrical resistance decreased for the first six hours of testing, then increased between six and nine hours of testing. The increase in the 
temperature during the combined testing caused larger fluctuations compared to the lower levels of temperature applied.

3. Different wire deformation patterns have been identified in each combination of loading conditions. Vibration testing as a single loading condition has caused the collapse of wires which landed onto the bonding pad causing short circuiting. Also, the wires oriented vertically to direction of the vibration deformed more severely compared to other directions, following one direction. Vibration testing at either $180^{\circ} \mathrm{C}$ or $250^{\circ} \mathrm{C}$ caused mechanical softening and consequently severe deformation of the wires especially for the large loop ones.

\section{Acknowledgments}

The authors would like to thank Inseto Limited (Andover, UK) for their technical support and guidance through the wire bonding process and the Manufacturing Technology Centre (MTC) (Ansty Park, Coventry, UK) for providing the facilities and assistance for the shear and pull testing. The authors would also like to acknowledge GE Aviation Systems (Newmarket, Suffolk, UK) for their invaluable support and guidance through the experimental process and analysis.

\section{References}

[1]. Harman, G., "Wire bonding in microelectronics - materials, processes, reliability and yield", McGraw-Hill, $3^{\text {rd }}$ Edition, 2010.

[2]. Charles Jr, HK., "Microelectronics packaging: Electrical Interconnections", in: “Encyclopaedia of materials: Science and Technology”, Elsevier Science Ltd., pp. 5616$5635,2001$. 
[3]. Murali, S, Srikanth, N, Vath III, CJ, “An analysis of intermetallics formation of gold and copper ball bonding on thermal aging III, Mater. Res. Bull. 38 (2003) 637-646.

[4]. Philofsky, E, "Intermetallics formation in gold-aluminium systems, Solid-state electron. 13 (1970) 1391-1399

[5]. Shepherd, D., Grant, P.S., Johnston, C., Riches, S., "The behaviour of Au-Au wire bonds in extreme environments", HITEC Conference, 2010.

[6]. Mirgkizoudi M., Liu C., Riches S., "Reliability testing of electronic packages in harsh environments”, Electronics Packaging Technology Conference, pp. 224-230, 2010.

[7]. Kamaludin, K.A., Mirgkizoudi, M., Liu, C., Riches, S., "Effects of combined thermal and vibration loadings on wire bond integrity", International Conference on Electronic Packaging Technology \& High Density Packaging, pp. 828-831, 2011.

[8]. Mirgkizoudi, M., Liu, C., Conway P., Riches S., "Combined Temperature and Vibration Testing for Wire Bond Interconnections in Harsh Environment Electronics", International Conference on High Temperature Electronics, pp. 335-344, 2012.

[9]. RTCA Aviation Standard DO-160E, "Environmental Conditions and Test Procedures for Airborne Equipment", Washington, 2004.

[10]. JEDEC Solid State Technology Association, JEDEC Standard JESD22-B116A, “Wire Bond Shear Test Method”, U.S.A, August 2009.

[11]. U.S.A Military Standard 883H, “Test Method Standard - Microcircuits", U.S.A. Department of Defence, Method 2010.10, 2004.

[12]. Steinberg, DS, "Vibration Analysis for Electronic Equipment”, John Wiley \& Sons, Inc., $3^{\text {rd }}$ Edition, 2000.

[13]. Kung, HK, Chen, HS, Lu, MC, “The Wire Sag Problem in Wire Bonding Technology for Semiconductor Packaging", Journal of Microelectronics Reliability, 2013;53(2): 288-296.

[14]. Kung, HK, Chen, HS, Jou, JM, Hsu, HC, “The Experimental Measurement of Wire Sag of Long Wire Bonds for 3-dimentiona and Multi-chip Module Packaging", 
proceedings of $4^{\text {th }}$ International Microsystems, Packaging, Assembly and Circuits Technology Conference (iMPACT), 21-23 October, Taipei, 2009. 
Mechanical and electrical characterisation of $\mathrm{Au}$ wire interconnects in electronic packages under the combined vibration and thermal testing conditions

M. Mirgkizoudi, C. Liu, P.P. Conway, S. Riches

\section{Highlights}

- The ball shear strength levels drop drastically after the combined testing while the wire pull strength levels remain high.

- For all the combined testing conditions, the electrical resistance decreases for the first six hours of testing, then increases between six and nine hours of testing.

- Wires orientated vertically towards the direction of vibration undergo more severe deformation. 


\title{
Mechanical and electrical characterisation of $\mathrm{Au}$ wire interconnects in electronic packages under the combined vibration and thermal testing conditions
}

\author{
M. Mirgkizoudi, C. Liu, P.P. Conway, S. Riches
}

The authors would like to sincerely thank the reviewers for taking the time to review the manuscript and make all the valuable comments that certainly improved its quality. Below are the authors' responses to the comments of each reviewer. The authors also highlight the changes that have been made (point by point) as raised in the comments in Italic font.

\section{Reviewer\#1 (changes in manuscript highlighted in yellow):}

1. In Figs. 1 and 2, include coordinate axes and relate to the directions when describing the vibration experiment. In which direction are the vibrations?

The coordinate axis and the direction of vibration have been included in Section 2.2 in Figure 3.

2. Inconsistent information at "Experimental Details" section

a. It said 48-pin DIL device is used in that section, however, in "Abstract" and Figure 1 caption it is said to be 40 pin. Make consistent.

The mistake of 40-pin instead of 48 has been corrected in the abstract section.

b. PDF page 9: "Forty-eight.....and forty-four for the wire pull strength...." These numbers are per sample/package. The total amount of bonds required to complete this study is much higher. Please add explanation or correction.

Explanation has been given in Section 2.3.

3. Separate sections for "Results" and "Discussion"

a. There are too much information in one section which at times become overwhelming. Please split into two sections.

"Results" and "Discussion" are now in two separate sections.

4. Use " $25^{\circ} \mathrm{C}$ " instead of "room temperature" in "Results \& Discussion" section if that is what you mean.

"room temperature" has been replaced with " $25^{\circ} \mathrm{C}^{\prime}$ throughout the manuscript.

5. Last line of PDF page 12: "...failed ball bonds was recorder for..."

a. Should be saying "recorded" not "recorder".

Mistake has been corrected.

6. Add reference for each of the following and correct number where necessary:

a. PDF page 13: "military standard minimum of $3 \mathrm{~g}(\mathrm{f})$ "

Reference has been added

b. PDF page 13: last line: "... which could explain the lower pull force values". 
"lower" has been replaced with "low" which was the authors initial intention.

c. PDF page 26: "..industry's minimum of $30 \mathrm{~g}(\mathrm{f}) \ldots "$

Reference has been added.

7. Quantify the comparative results

a. PDF page 17: "...a reduction in the wire yield strength was observed..." how much? Provide quantitative data of the difference.

The statement has been rephrased as the reduction in the yield strength was a hypothesis. The change can be found in Section 4 -Discussion-Sub-section 4.1, first paragraph

b. PDF page 23: "...Both failure modes are associated with changes in the loop..." how many bonds failed in first mode and how many in second mode? Provide quantitative data.

A table with quantitative results has been added. See Table 3 in the manuscript.

c. Compared Major results (such as, pull strength variation due to temperature change) using a graph or a table.

At this stage of the work the ball shear and wire pull strength has not been measured for a purely thermal environment. Extended work on this subject will be present in a manuscript in the near future.

8. Add further clarification on how the 4-point measurements are performed for electrical resistance measurement. (PDF page 18) 9. Add an explanation of possible reason why resistance values change after 6 hours.

Further clarification on how the electrical resistance measurements have been performed has been added. For the possible reason why resistance values change after 6 hours please refer to Discussion - Electrical Performance section.

9. Add further clarification on the second statement of "Conclusion".

a. "..they would not affect the general performance of the system." Why not? Add further clarification not in the conclusions but in the discussion section.

The statement has been removed as the degree on which the recorded changes in the electrical resistance can affect the general performance of the system is not yet clear.

10. Figs. 4 to 9 should be improved. Titles information should be move to figure caption (leave no titles). It is recommended to compress the data as boxplots in two figures only for clarity and better comparability: one figure for shear data, the second for pull.

The data in Fig. 4 to 9 have been compressed and Fig. 4 to 9 have been replaced with Fig 5 and 6

\section{$\underline{\text { Reviewer\#2 (changes in manuscript highlighted in green): }}$}

1. In Sec.2.1 wire bonding conditions, what bonding temperature was applied? 
The bonding temperature has been added in Table 1.

2. As the shear test comparing the bond interface strength versus the bond ball diameter (deformed severity), the bonded ball diameter in addition to the target $75 \mathrm{um}$ ball size needs to be referenced.

Reference has been added.

3. Was the DIP package in test hermetically sealed? In what kind (gas) environment when heating test? What was the exact device (bond) temperature when the hot plate heating at the targeted testing temperature in testing? What was the heating profile? Was heating applied prior vibration or the vibration applied once the target temperature reached? Such detailed testing conditions may be needed to add for future reference.

Further description of the testing profile has been included in Section 2.2.

4. What was the gold wire composition in test? which is needed to contrast the $1 \%$ Si dopant suggested in the conclusion and its strength (related wire properties may be also needed). The composition of the gold wire has been added in the document.

5. What kind of gold plate pads in DIP package? Thickness? Composition? Related mechanical properties?

These information are unknown

6. In Sec.2.3, how was the 4 point probe measurement applied to the bonding diagram with a common Au pad?

Further clarification on how the electrical resistance measurements have been performed has been added.

7. In Sec.3.1 measurement results, the sample size of each measurement needs to be specified. How many DIPs were measured? or, the results were averaged from all the bonds in one package with the targeted bonding profile? This may lead to the question of the conclusion validity of measured bond strength upon bond directions. Explanation has been given in Section 2.3.

8. The pull/shear test failure modes must be specified in order to judge together with its strengths because each testing intends to test different aspects of bond goodness.

The failure modes are described in Section 4.1.

9. In order to compare the bond strength migration, what were the as-bonded bond strength values?

Strength values for the as-bonded state have been added in Table 2.

10. In Sec.3.1, it is stated 'Fatigue due to temperature applied and stresses caused on the wire bonds due to the vibration loading are believed to be the main reasons for such a significant reduction of the mechanical strength levels.' Is there any evidence such as photos and/or other analysis to support such statement? 
The sentence has been revised as it was a hypothesis made by the authors and not a statement based on results. The changes can be found in Section 4 - Discussion - Subsection 4.1, first paragraph

11. In Sec.3.2, it touched the wire deformation after vibration test. The questions are followed as: How many wire deformation observed? Consistent in certain bond position? More sever in certain vibration direction?

A table with quantitative results has been added. See Table 3.

For the vibration direction please refer to section 4.3

\section{Reviewer\#3 (changes in manuscript highlighted in light blue):}

1. The number of wire bonds per year is grossly underreported. Even the number of packages is higher that the supposed number of bonds.

The number of packages has been updated in "Introduction", first paragraph.

2. It might have been instructive to report the failure mode distribution for shear and pull testing. The nomenclature for the failure modes is well established.

The failure modes are described in Section 4.1.

3. Likewise, SEM graphs of some typical failures would have been enlightening.

The authors felt that this was not the scope of the work and thus no SEM pictures have been taken of the failure modes that have been observed although they are described in Section 4.1.

4. What is a possible reason for the degradation of the shear values while the pull values remained rather robust?

Please refer to Section 4.1.

5. The test data is rather short time. The field use conditions as well as reliability test standards reach thousands of hours. It would be interesting to see what the long term effects of the stresses would be and then draw conclusions about the small albeit consistent resistance changes.

The long term effects of the stresses are currently being examined and the results will be presented in the near future. However, the effects of the combined conditions were visible only after a few hours of testing.

\section{Reviewer\#4 (changes in manuscript highlighted in pink):}

This is a good paper. It is on a subject that has been worked on for many years, but is for a specialized niche in wire bonding. This reviewer felt that the properties of this $\mathrm{Au}$ wire should be included (Au is doped to improve the neck above the ball -without such the loop could not be uniquely formed. The dopants also effect the mechanical props of the entire system. The manufacturers are secretive about what and how much of what --in $<50$ ppm-- is 
added. My only suggestion is that you continue working with Mfgs. based in Japan and Europe and see if the high temp vibration results are different. Another experiment would be to use a better wire bonder that makes the loop and bonds absolutely the same length and appearance in the future, and the bonds absolutely identical in length and loop height so the mech. props are identical. If not the wire resonance could/would be different, possibly causing differences observed. A good production autobonder (not a semiauto.)would be much! better for that experiment. This is good work and valuable to your very--specialized community! (I note that they have given it to several conferences and presumably added explanations from comments?)

The authors would like to thank this reviewer for his kind comments and suggestions. The Au wire used in this work was a 99.9\% pure Au wire, no further information on the properties of the wire are known. 